\section{Carmen García-Ruiz \\ Antonio L. Crego \\ M. Luisa Marina}

Departamento de Química

Analítica, Facultad de Química,

Universidad de Alcalá,

Alcalá de Henares (Madrid),

Spain

\title{
Comparison of charged cyclodextrin derivatives for the chiral separation of atropisomeric polychlorinated biphenyls by capillary electrophoresis
}

\begin{abstract}
Charged cyclodextrin (CD) derivatives were used as chiral selectors in electrokinetic chromatography (EKC) for the chiral separation of highly hydrophobic neutral racemates such as atropisomeric polychlorinated biphenyls (PCBs). $\beta-C D$-phosphated, $\beta$-CD sulfated, succinylated- $\gamma-C D$ (Succ- $\gamma-C D)$ and succinylated- $\beta-C D$ (Succ- $\beta-C D)$ were used as anionic CDs. As cationic CD, 6-monodeoxy-6-monoamino- $\beta-C D\left(\beta-C D-\mathrm{NH}_{2}\right)$ was tested for the first time in order to separate PCBs. From the different CD derivatives employed, the best separations were obtained with the cationic $C D$ derivative. Thus, the use of $\beta-C D-\mathrm{NH}_{2}$ in phosphate buffer at $\mathrm{pH} 2.0$ containing urea allowed the chiral recognition of eleven PCBs $(45,84,88,91,95,131,136,144,149,176$, and 197). In this case, the addition of $2 \mathrm{~m}$ urea to the buffer solution was crucial to achieve the chiral separation of PCBs. The addition of acetonitrile to $10 \mathrm{~mm}$ phosphate buffer $(\mathrm{pH} 2.0)$ with $30 \mathrm{~mm} \beta-\mathrm{CD}-\mathrm{NH}_{2}$ and $2 \mathrm{~m}$ urea improved considerably the chiral resolution obtained for PCBs 91, 95, 136, 144, 149, and 197 although an increase in the analysis time was also observed. All the results obtained were compared with those previously obtained with the dual $C D$ system carboxymethyl- $\gamma-C D / \beta-C D$.
\end{abstract}

Keywords: Chiral capillary electrophoresis / Cyclodextrin derivatives / Polychlorinated biphenyls DOI 10.1002/elps.200305465

\section{Introduction}

In the last decade, capillary electrophoresis (CE) has shown to be very suitable for the separation of racemates, being cyclodextrins (CDs) added to the running electrolyte the most used chiral selectors [1-4]. The use of CE for chiral separations has three major advantages in comparison with HPLC: the low consumption of the chiral selector (reduced costs), high efficiencies, and high selectivity [5]. Besides the oftenused neutral CDs, the use of charged CD derivatives has expanded the range of applicability of this technique for chiral analysis [6]. The growing use of charged CDs for the enantioseparation of a wide range of enantiomers can be attributed to three important facts: (i) their ability to perform fast chiral separations at low concentrations; (ii) the possible chiral separation of neutral and charged racemates; and (iii) the effect that the introduction of ionogenic groups on the CD rim, or connected to it via a short alkyl chain, has on the enhancement of the solubility

Correspondence: Dr. M. Luisa Marina, Departamento de Química Analítica, Facultad de Química, Universidad de Alcalá, Ctra. Madrid Barcelona Km. 33.600, E-28871 Alcalá de Henares (Madrid), Spain

E-mail: mluisa.marina@uah.es

Fax: $+34-91-8854971$

Abbreviations: PCB, polychlorinated biphenyl; CM- $\boldsymbol{\beta}-\mathbf{C D}$, carboxymethylated $\beta$-cyclodextrin; PM- $\beta$-CD, methylated $\beta$-cyclodextrin of charged CDs in aqueous media [7, 8]. In addition, the enantioseparation of neutral analytes, which can be performed using charged micelles mixed with neutral CDs, can be carried out using charged CDs, which confers a nonzero mobility, without micelles. These systems are more compatible with organic solvents and more predictable than micellar systems where surfactant monomers can be included into the $C D$ cavity and thereby participate in the complexation with the analyte.

Recently, it has been shown that the potential of CE for enantiomeric separations has increased considerably with the use of anionic CDs [6, 9]. However, the use of cationic CDs has not been extensively reported probably due to the high price and low commercial availability. About 20 papers have been published using cationic CDs as chiral selectors [7, 8, 10-31] since in 1989 Terabe [10] was the first to introduce a cationic CD for chiral separation by CE. All of them have shown the possibilities of these CDs to perform the enantiomeric separation of analytes in pharmaceutical analysis, being the most common application the separation of carboxylic acids or amino acids. Only in five studies, besides drugs, phenoxy acid herbicides [7, 8, 29 and 30], and pyrethroic acids [31] were enantioseparated.

The neutral racemates studied in this work are atropisomeric polychlorinated biphenyls (PCBs) which are a class of synthetic chlorinated aromatic compounds that consti- 
tute an important class of priority pollutants classified by the US Environmental Protection Agency (EPA) as carcinogens [32, 33]. Only 19 of these PCBs are chiral compounds configurationally stable at room temperature due to the restricted rotation about the $\mathrm{C}-\mathrm{C}$ bond with estimated energy barriers between 105-240 kJ/mol, being these PCBs configurationally stable at the working temperatures in $\mathrm{CE}$ (normally, between 10 to $60^{\circ} \mathrm{C}$ ) due to they are also configurationally stable (energy barriers higher than $100 \mathrm{~kJ} / \mathrm{mol}$ ) at temperatures as high as $300^{\circ} \mathrm{C}$, as has been reported by Schurig et al. [34, 35]. The existence of axial chirality in PCBs molecules is the reason for which they are called atropisomers. Some chiral PCBs have been enantioresolved by CE using different chiral selectors: $\gamma$-CD $[36,37]$ or mixtures of $\beta-C D$ and $\gamma-C D$ [38] with sodium dodecyl sulfate (SDS) micelles; bile salts alone [39, 40] or mixed with SDS micelles and $\gamma-C D$ [40]; and a dual CD system constituted by carboxymethylated $\gamma-C D(C M-\gamma-C D)$ and $\beta-C D$ or methylated $\beta-C D(P M-\beta-C D)[41,42]$. The aim of this work is to compare the possibilities of the use of different charged CDs in electrokinetic chromatography (EKC) for the enantiomeric separation of highly hydrophobic racemates such as atropisomeric PCBs.

\section{Materials and methods}

\subsection{Reagents}

All reagents employed were of analytical grade. Sodium dihydrogen phosphate dihydrate, dimethylformamide (DMF), sodium hydroxide, and hydrochloric acid were supplied from Merck (Darmstadt, Germany); $\beta-C D$ and urea were from Fluka (Buchs, Switzerland); acetonitrile and methanol were from Labscan (Dublin, Ireland); isopropanol was from Scharlau (Barcelona, Spain). 6-Monodeoxy-6-monoamino- $\beta-\mathrm{CD}$ hydrochloride $\left(\beta-\mathrm{CD}-\mathrm{NH}_{2}\right.$, degree of substitution (d.s.) $=1$ ), succinylated $\beta-C D$ (Succ- $\beta-C D$, d.s. $=3.5)$, succinylated $\gamma-C D($ Succ- $\gamma-C D$, d.s. $=3), \beta-C D$ sulfate sodium salt $(\beta-C D$ sulfated, d.s. $=$ $11)$, and $\beta-C D$ phosphate sodium salt ( $\beta-C D$ phosphated, d.s. = 6) were obtained from Cyclolab (Budapest, Hungary). Water used to prepare solutions was purified through a Milli-Q system from Millipore (Bedford, MA, USA). All solutions were filtered prior use through $0.45 \mu \mathrm{m}$ pore size disposable nylon filters from Scientific Resources (Eatontown, NJ, USA). The 19 PCBs studied were supplied by Dr. Ehrenstorfer Reference Materials (Augsburg, Germany). The basic structure and IUPAC number of the compounds used throughout this study according to Ballschmiter nomenclature [43] are shown in Table 1.
Table 1. Basic structure, IUPAC numbers (according to Ballschmiter and Zell nomenclature [43]) and systematic names for the chiral PCBs studied

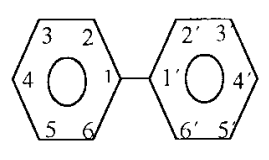

\begin{tabular}{|c|c|}
\hline IUPAC No. & PCB name \\
\hline 45 & 2,2’,3,6-Tetrachlorobiphenyl \\
\hline 84 & 2,2',3,3',6-Pentachlorobiphenyl \\
\hline 88 & 2,2',3,4,6-Pentachlorobiphenyl \\
\hline 91 & 2,2',3,4',6-Pentachlorobiphenyl \\
\hline 95 & $2,2^{\prime}, 3,5^{\prime}, 6$-Pentachlorobiphenyl \\
\hline 131 & 2,2',3,3',4,6-Hexachlorobiphenyl \\
\hline 132 & 2,2',3,3',4',6-Hexachlorobiphenyl \\
\hline 135 & 2,2',3,3',5',6-Hexachlorobiphenyl \\
\hline 136 & 2,2',3,3',6,6'-Hexachlorobiphenyl \\
\hline 139 & 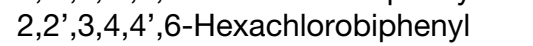 \\
\hline 144 & 2,2',3,4,5',6-Hexachlorobiphenyl \\
\hline 149 & 2,2',3,4',5',6-Hexachlorobiphenyl \\
\hline 171 & $2,2^{\prime}, 3,3^{\prime}, 4,4^{\prime}, 6$-Heptachlorobiphenyl \\
\hline 174 & $2,2^{\prime}, 3,3$ ', $4,5,6$ '-Heptachlorobiphenyl \\
\hline 175 & $2,2^{\prime}, 3,3^{\prime}, 4,5^{\prime}, 6$-Heptachlorobiphenyl \\
\hline 176 & $2,2^{\prime}, 3,3^{\prime}, 4,6,6^{\prime}$-Heptachlorobiphenyl \\
\hline 183 & 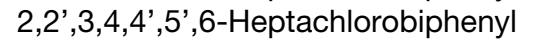 \\
\hline 196 & $2,2^{\prime}, 3,3$ ',4,4',5',6-Octachlorobiphenyl \\
\hline 197 & $2,2^{\prime}, 3,3^{\prime}, 4,4^{\prime}, 6,6^{\prime}$-Octachlorobiphenyl \\
\hline
\end{tabular}

\subsection{Apparatus}

We used an HP3D CE system (Hewlett-Packard, Waldbronn, Germany) equipped with an on-column diode array detector (DAD) and HP 3D-CE Chemstation software. Separations were performed on untreated fusedsilica capillaries of $50 \mu \mathrm{m}$ ID and $375 \mu \mathrm{m}$ OD, purchased from Composite Metal Services (Worcester, England). Capillaries had a total length of $58.5 \mathrm{~cm}$ and $50 \mathrm{~cm}$ to the detector. Capillary temperature was $45^{\circ} \mathrm{C}$ (except for some experiments with the $\beta-\mathrm{CD}-\mathrm{NH}_{2}$ in which a temperature of $60^{\circ} \mathrm{C}$ was employed) and UV detection was performed at $230 \mathrm{~nm}$. A $654 \mathrm{pH}$-meter from Metrohm (Herisau, Switzerland) was employed to adjust the $\mathrm{pH}$ of the separation buffers.

\subsection{Procedure}

Separation buffers were prepared in order to dissolve the appropriate amount of buffer, CD derivatives, and urea into water to achieve the desired concentration. When acetonitrile or alcohols (methanol or isopropanol) were added to the buffer solution, the $\mathrm{pH}$ was adjusted before the addition of these organic modifiers. Finally, the $\mathrm{pH}$ was adjusted to 2.0 or 7.0 with solutions of $1 \mathrm{M}$ or $0.1 \mathrm{M}$ 
hydrochloric acid or $1 \mathrm{~m}$ or $0.1 \mathrm{~m}$ sodium hydroxide, respectively. Sample solutions were prepared by dissolving each $\mathrm{PCB}$ in DMF to achieve a final concentration of approximately $0.2 \mathrm{mg} / \mathrm{mL}$. Before first use, a new capillary was rinsed with $1 \mathrm{~m} \mathrm{NaOH}$ for $30 \mathrm{~min}$, followed by a 30 min rinse with water. Between introduction of samples, the capillary was conditioned with water for $2 \mathrm{~min}, 0.1 \mathrm{~m}$ sodium hydroxide for $2 \mathrm{~min}$, water for 2 min followed by separation buffer for $4 \mathrm{~min}$ when phosphate solutions at $\mathrm{pH} 7.0$ were used. When phosphate solutions at $\mathrm{pH} 2.0$ were employed, the capillary conditioning consisted of $0.1 \mathrm{~m}$ hydrochloric acid for $2 \mathrm{~min}$ followed by separation buffer for $4 \mathrm{~min}$. Injections were made by pressure (from $20 \mathrm{mbar}$ for $3 \mathrm{~s}$ to $50 \mathrm{mbar}$ for $2 \mathrm{~s}$ ) and the applied voltage was of $20 \mathrm{kV}$. Enantiomeric resolution was calculated by the following expression:

$R_{\mathrm{s}}=1.18\left(t_{2}-t_{1}\right) /\left(w_{1}+w_{2}\right)$

where $t_{1}$ and $t_{2}$ are the two enantiomers migration times and $w_{1}$ and $w_{2}$ are the peak widths at half height.

\section{Results and discussion}

\subsection{Enantiomeric separation of chiral PCBs using anionic $C D$ s as chiral selectors}

In a previous work [41] the chiral separation of PCBs was performed using a dual CD system based on $C M-\gamma-C D$ and $\beta-C D$ or $P M-\beta-C D$ where the anionic $C D$ only acted as carrier of the neutral analytes being the neutral CD added the chiral selector. In fact, chiral separation of PCBs was not possible using the anionic CD alone in the separation buffer. In this work, the possibilities of other anionic commercial CDs ( $\beta-C D$ phosphated, $\beta-C D$ sulfated, Succ- $\gamma-C D$, and Succ- $\beta-C D$ ) as well as one cationic $\mathrm{CD}\left(\beta-\mathrm{CD}-\mathrm{NH}_{2}\right)$ in order to achieve the chiral separation of the atropisomeric PCBs have been studied and compared. Table 2 shows all the experimental conditions tested with anionic CDs in order to achieve the chiral separation of the group of 19 chiral PCBs configurationally stable at room temperature (see Table 1). In these experiments, a $10 \mathrm{~mm}$ phosphate buffer at $\mathrm{pH} 7.0$ was

Table 2. Experimental conditions tested for the chiral separation of PCBs using anionic CDs ${ }^{a)}$

\begin{tabular}{|c|c|c|c|c|}
\hline $\begin{array}{l}\text { Background } \\
\text { electrolyte }\end{array}$ & Chiral selector & Additive & $\begin{array}{l}\text { Current } \\
\text { intensity }(\mu \mathrm{A})\end{array}$ & $\begin{array}{l}\text { PCB chirally } \\
\text { separated }\left(R_{\mathrm{s}}\right)\end{array}$ \\
\hline & $10 \mathrm{~mm} \beta-C D$ phosphated & 2 м urea & 110 & None \\
\hline & & 5 м urea & 78 & None \\
\hline & $10 \mathrm{~mm} \beta-C D$ sulfated & 2 м urea & 71 & None \\
\hline & & $5 \mathrm{~m}$ urea & 61 & None \\
\hline & $10 \mathrm{~mm}$ Succ- $\gamma-C D$ & $2 \mathrm{~m}$ urea & 25 & None \\
\hline & $20 \mathrm{~mm}$ Succ- $\gamma-C D$ & $2 \mathrm{~m}$ urea & 27 & None \\
\hline & $5 \mathrm{~mm}$ Succ- $\beta-C D$ & 2 м urea & 21 & $136(0.4) ; 197(0.2)$ \\
\hline & $10 \mathrm{~mm}$ Succ- $\beta-C D$ & $2 \mathrm{~m}$ urea & 28 & $144(0.4) ; 176(0.4) ; 183(0.5)$ \\
\hline & $20 \mathrm{~mm}$ Succ- $\beta-C D$ & 2 м Urea & 48 & $131(0.4) ; 132(0.3) ; 144(0.3)$ \\
\hline \multirow{9}{*}{$\begin{array}{l}10 \mathrm{~mm} \text { phosphate } \\
(\mathrm{pH} 7.0)\end{array}$} & 30 mм Succ- $\beta-C D$ & 2 м urea & 58 & $149(0.4)$ \\
\hline & & None & 34 & None \\
\hline & & $4 \mathrm{~m}$ urea & 27 & None \\
\hline & & $\begin{array}{l}2 \mathrm{~m} \text { urea }+10 \% \\
\text { acetonitrile }\end{array}$ & 29 & $176(0.4) ; 197(0.3)$ \\
\hline & 10 mм Succ- $\beta-C D$ & $\begin{array}{l}2 \mathrm{~m} \text { urea }+50 \% \\
\text { acetonitrile }\end{array}$ & 19 & None \\
\hline & & $\begin{array}{c}2 \mathrm{~m} \text { urea }+10 \% \\
\text { methanol }\end{array}$ & 29 & None \\
\hline & & $\begin{array}{l}2 \mathrm{M} \mathrm{urea}+10 \% \\
\text { isopropanol }\end{array}$ & 25 & None \\
\hline & $10 \mathrm{~mm}$ Succ- $\beta-C D+10 \mathrm{~mm} \beta-C D$ & $2 \mathrm{~m}$ urea & 21 & None \\
\hline & $10 \mathrm{~mm}$ Succ- $\beta-C D+3 \mathrm{~mm} \beta-C D$ & $2 \mathrm{~m}$ urea & 23 & None \\
\hline
\end{tabular}

a) Instrumental conditions: untreated fused-silica capillary, $58.5 \mathrm{~cm}(50 \mathrm{~cm}$ to the detector window) $\times 50 \mu \mathrm{m} \mathrm{ID;} \mathrm{UV} \mathrm{detec-}$ tion at $230 \mathrm{~nm} ; 45^{\circ} \mathrm{C} ; 20 \mathrm{kV}$ 
used to ensure the anionic form of the ionizable CDs used. A low concentration of this buffer was used because the addition of ionic CDs to the buffer solution increases the current intensity and it is recommendable to work at low current intensities $(<100 \mu \mathrm{A})$. In addition, according to previous works dedicated to the chiral separation of PCBs [36-41], urea was used as additive in order to increase the solubility of the neutral highly hydrophobic PCBs and CDs in the aqueous buffer solution. Under these conditions, the use of $\beta-C D$ phosphated, $\beta-C D$ sulfated, and Succ- $\gamma-C D$ did not enable the chiral separation of any of the PCBs studied. This could be the cause in the case of $\beta-C D$ phosphated and $\beta-C D$ sulfated to the high charge density of these CDs [6], which is related to their degree of substitution (see Section 2.1). In the case of Succ- $\gamma$-CD which has a similar charge density than Succ- $\beta-C D$, the absence of chiral discrimination could be due to the higher cavity size of Succ- $\gamma-C D$ which could avoid the solute-CD chiral interactions. Nevertheless, Succ- $\beta-C D$ enabled to observe a slight chiral discrimination of some PCBs as it is shown in Table 2. In order to increase the chiral discrimination observed for PCBs when $10 \mathrm{~mm}$ Succ- $\beta$-CD in phosphate buffer at $\mathrm{pH} 7.0$ was used, different additives were tested. From the different concentrations of urea used, the addition of $2 \mathrm{~m}$ urea enabled the chiral discrimination of a higher number of PCBs (see Table 2). When $2 \mathrm{M}$ urea was employed the effect of different organic modifiers was studied. Thus, the use of acetonitrile, methanol or isopropanol in the buffer solution showed that only the use of $10 \%$ acetonitrile enabled the partial chiral separation $\left(R_{\mathrm{s}} \leq 0.4\right)$ of two PCBs as it can be seen in Table 2. Finally, mixtures of Succ- $\beta-C D / \beta-C D$ were used but the results showed that any PCB was enantiomerically separated, which could be probably due to a competitive effect of both CDs by the PCB because both CDs act as chiral selectors for PCBs [44].

\subsection{Enantiomeric separation of chiral PCBs using a cationic CD as chiral selector}

The possibility of a commercial cationic $C D$ on the chiral separation of the 19 chiral PCBs studied was also investigated in this work. The cationic CD $\beta-C D-\mathrm{NH}_{2}$ used is a basic $C D$, which has one of its primary hydroxyl groups substituted by an amine function. This CD has an estimated $\mathrm{p} K_{\mathrm{a}}$ of 8.2 , then at acid $\mathrm{pH}$ this $\mathrm{CD}$ is positively ionized [15]. On the other hand, at $\mathrm{pH}$ lower or equal to 2 the electroosmotic flow (EOF) is suppressed [45] and the neutral analytes investigated, without self-electrophoretic mobility, only will migrate to the detector when they are complexed with the charged CD. In addition, under these conditions the silanol groups on the capillary surface are not charged avoiding the adsorption of the positively charged CD to the inner wall of the capillary. Phosphate buffer at $\mathrm{pH} 2.0$ was employed.

The influence of $\beta-C D-\mathrm{NH}_{2}$ concentration (from 5 to $30 \mathrm{~mm}$ ) upon the chiral separation of the 19 chiral PCBs studied was investigated using a $50 \mathrm{~mm}$ phosphate buffer $(\mathrm{pH} 2.0)$ containing $2 \mathrm{M}$ urea. A temperature of $60^{\circ} \mathrm{C}$ was chosen in order to decrease the viscosity of the electrolytic solution favoring the mobility of the cationic CD and decreasing the analysis time due to the fact that under the working conditions an EOF flow does not exist. Under these conditions, the chiral recognition of four PCBs (2,2',3,6-tetrachloro; 2,2',3,4',6-pentachloro; 2,2',3,5',6pentachloro; 2,2',3,4',5',6-hexachloro) from the 19 studied chiral PCBs was observed. In general, the chiral resolution increased when the CD concentration increased being 20 or $30 \mathrm{~mm}$ the most appropriate concentrations (see Table 3). Higher concentrations of this cationic CD were not used because the current intensity was higher than $190 \mu \mathrm{A}$ (the current intensity increases with the concentration of the charged $\left.\beta-\mathrm{CD}-\mathrm{NH}_{2}\right)$. Figure 1 shows the chiral separation of PCB 45 (2,2',3,6-tetrachloro), PCB 91 (2,2',3,4',6-pentachloro), PCB 95 (2,2',3,5',6-pentachloro), and PCB 149 (2,2',3,4',5',6-hexachloro) using the above-mentioned conditions, being only the atropisomers of PCB 95 (2,2',3,5',6-pentachloro) and PCB 149 $\left(2,2^{\prime}, 3,4^{\prime}, 5^{\prime}, 6\right.$-hexachloro) baseline-resolved.

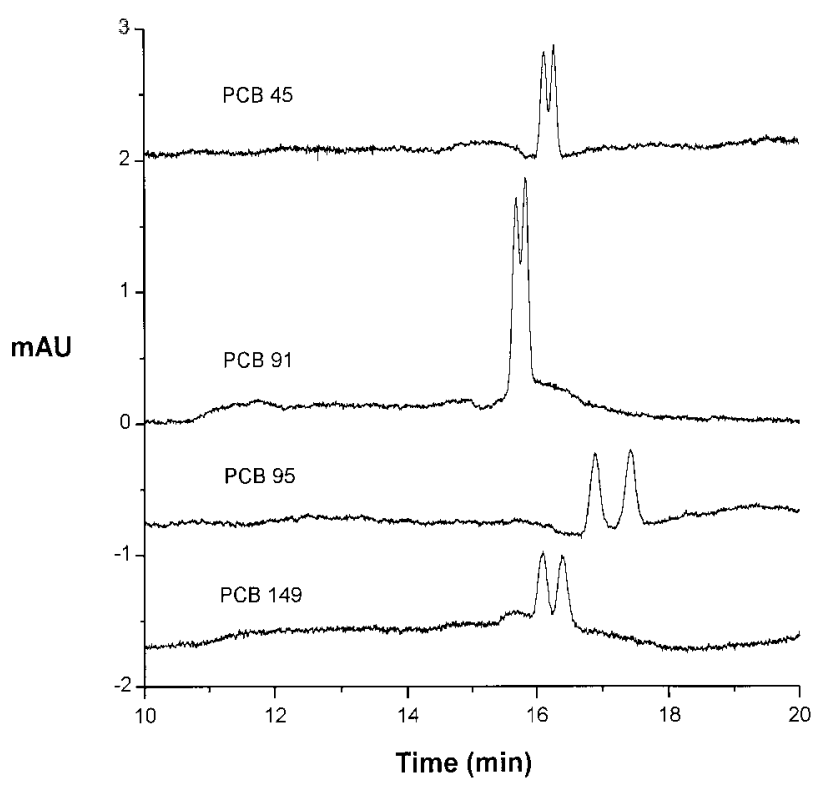

Figure 1. Electropherograms corresponding to the chiral separation of PCBs 45, 91, 95, and 149 in $50 \mathrm{~mm}$ phosphate buffer ( $\mathrm{pH} 2.0$ ) containing $30 \mathrm{~mm} \beta-\mathrm{CD}-\mathrm{NH}_{2}$ and $2 \mathrm{M}$ urea. Injection by pressure, $20 \mathrm{mbar}$ for $3 \mathrm{~s}$; temperature, $60^{\circ} \mathrm{C}$; capillary, $58.5 \mathrm{~cm}(50 \mathrm{~cm}$ to the detector $\times 50 \mu \mathrm{m} \mathrm{ID}$; applied voltage, $20 \mathrm{kV}$; UV detection at $230 \mathrm{~nm}$. 
The effect of the addition of a second $C D(\beta-C D)$ to a $50 \mathrm{~mm}$ phosphate buffer ( $\mathrm{pH} 2.0$ ) containing $20 \mathrm{~mm} \beta-\mathrm{CD}-\mathrm{NH}_{2}$ and $2 \mathrm{~m}$ urea was also studied. In this case, a similar effect was observed when $\beta-C D$ was added to the cationic $\beta-C D-\mathrm{NH}_{2}$ in comparison when this neutral CD was added to the anionic Succ- $\beta-C D$. Thus, in the system Succ- $\beta-C D / \beta-C D$ the partial resolution $\left(R_{\mathrm{s}} \leq 0.5\right)$ of $\mathrm{PCB} 144\left(2,2^{\prime}, 3,4,5^{\prime}, 6\right.$-hexachloro), PCB 176 (2,2',3,3',4,6,6'-heptachloro), and PCB $183\left(2,2^{\prime}, 3,4,4^{\prime}, 5^{\prime}, 6\right.$-heptachloro) disappeared when the same concentration of both CDs was used (10 mM Succ$\beta-\mathrm{CD}+10 \mathrm{~mm} \beta-\mathrm{CD})$, and in the system $\beta-\mathrm{CD}-\mathrm{NH}_{2} / \beta-\mathrm{CD}$ the partial resolution $\left(R_{\mathrm{s}} \leq 0.7\right)$ of PCB 45 (2,2',3,6-tetrachloro) and PCB 91 (2,2',3,4',6-pentachloro) also disappeared when the same concentration of both CDs was employed ( $\left.20 \mathrm{~mm} \beta-\mathrm{CD}-\mathrm{NH}_{2}+20 \mathrm{~mm} \beta-\mathrm{CD}\right)$, observing a slight decrease in the enantiomeric resolution of PCB 95 (2,2',3,5',6-pentachloro) and PCB 149 (2,2',3,4',5',6-hexachloro) which, contrary to the other two PCBs (PCB 45 and 91), were almost baseline-separated. These results could be attributed to a competitive effect between both CDs ( $\beta-C D-\mathrm{NH}_{2}$ and $\beta-\mathrm{CD}$ or Succ- $\beta-\mathrm{CD}$ and $\left.\beta-\mathrm{CD}\right)$ by the PCBs due to in both cases both CDs have discriminated chirally PCBs.
In order to reduce the current intensity, the buffer concentration and the temperature were decreased. Thus, $10 \mathrm{~mm}$ phosphate buffer $(\mathrm{pH} 2.0)$ and $45^{\circ} \mathrm{C}$ were used to study the effect of the addition of different concentrations of urea on the chiral resolution of PCBs obtained when $30 \mathrm{~mm} \beta-\mathrm{CD}-\mathrm{NH}_{2}$ was used as chiral selector. Table 3 shows that the presence of urea is crucial in order to achieve the chiral resolution of PCBs. Thus, when the separation buffer was used without urea none of the PCBs was chirally separated. The addition of $1 \mathrm{~m}$ urea to the separation buffer only enabled the partial chiral resolution of the PCB 95 (2,2',3,5',6-pentachloro). When a concentration of $2 \mathrm{M}$ urea was used, the chiral recognition of eight PCBs was observed: PCB 84 (2,2',3,3',6-pentachloro), PCB 88 (2,2',3,4,6-pentachloro), PCB 95 (2,2', 3,5',6-pentachloro), PCB 131 (2,2',3,3',4,6-hexachloro), PCB 136 (2,2',3,3', 6,6'-hexachloro), PCB 149 (2,2', 3,4',5',6-hexachloro), PCB 176 (2,2',3,3',4,6,6'-heptachloro), and PCB 197 (2,2',3,3',4,4',6,6'-octachloro). This result is probably due to the increasing solubility of $\mathrm{PCBs}$ in the aqueous separation buffer. In this case, the stereoselectivity obtained was different to that obtained with a 50 mu phosphate buffer (pH 2.0) containing $30 \mathrm{~mm} \beta-\mathrm{CD}-\mathrm{NH}_{2}$

Table 3. Experimental conditions tested for the chiral separation of PCBs using cationic CDs ${ }^{\text {a) }}$

\begin{tabular}{|c|c|c|c|c|}
\hline $\begin{array}{l}\text { Background } \\
\text { electrolyte }\end{array}$ & Chiral selector & Additive & $\begin{array}{l}\text { Current } \\
\text { intensity }(\mu \mathrm{A})\end{array}$ & $\begin{array}{l}\text { PCB chirally } \\
\text { separated }\left(R_{\mathrm{s}}\right)\end{array}$ \\
\hline & $5 \mathrm{~mm} \beta-\mathrm{CD}-\mathrm{NH}_{2}$ & $2 \mathrm{~m}$ urea & 125 & None \\
\hline & $10 \mathrm{~mm} \beta-\mathrm{CD}-\mathrm{NH}_{2}$ & $2 \mathrm{~m}$ urea & 150 & $\begin{array}{l}45(0.7), 91(0.9), 95(1.5) \\
149(0.8)\end{array}$ \\
\hline & $20 \mathrm{~mm} \beta-\mathrm{CD}-\mathrm{NH}_{2}$ & 2 м urea & 160 & $\begin{array}{l}45(0.6), 91(0.7), 95(1.5) \\
\quad 149(1.2)\end{array}$ \\
\hline \multirow[t]{7}{*}{ 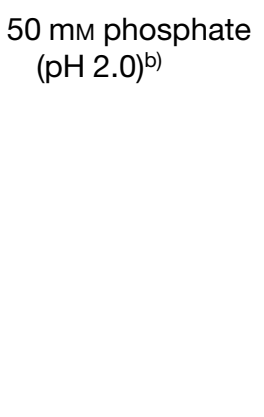 } & $30 \mathrm{~mm} \beta-\mathrm{CD}-\mathrm{NH}_{2}$ & 2 м urea & 185 & $\begin{array}{l}45(0.8), 91(0.6), 95(2.0) \\
149(1.3)\end{array}$ \\
\hline & $20 \mathrm{~mm} \beta-\mathrm{CD}-\mathrm{NH}_{2}+5 \mathrm{~mm} \beta-\mathrm{CD}$ & $2 \mathrm{~m}$ urea & 175 & $\begin{array}{l}45(0.5), 91 \text { (0.5), } 95(1.4) \\
149(0.7)\end{array}$ \\
\hline & $20 \mathrm{~mm} \beta-\mathrm{CD}-\mathrm{NH}_{2}+10 \mathrm{~mm} \beta-\mathrm{CD}$ & 2 м urea & 175 & 45 (0.5), 95 (1.6), $149(0.9)$ \\
\hline & $20 \mathrm{~mm} \beta-\mathrm{CD}-\mathrm{NH}_{2}+20 \mathrm{~mm} \beta-\mathrm{CD}$ & $2 \mathrm{~m}$ urea & 175 & $95(1.4), 149(0.6)$ \\
\hline & & None & 60 & None \\
\hline & & $1 \mathrm{~m}$ urea & 90 & $95(0.7)$ \\
\hline & & 2 м urea & 110 & $\begin{array}{r}84 \text { (1.2), } 88(0.8), 95(0.8) \\
131(1.0), 136(0.8), 149 \\
(0.9), 176(1.2), 197(0.6)\end{array}$ \\
\hline \multirow{3}{*}{$\begin{array}{l}10 \text { mm phosphate } \\
(\mathrm{pH} 2.0)^{\mathrm{c})}\end{array}$} & $30 \mathrm{~mm} \beta-\mathrm{CD}-\mathrm{NH}_{2}$ & $4 \mathrm{~m}$ urea & 175 & $95(1.8), 149(0.7)$ \\
\hline & & $\begin{array}{l}2 \mathrm{~m} \text { urea }+10 \% \\
\text { acetonitrile }\end{array}$ & 110 & $\begin{array}{l}91(1.5), 95(1.7), 136(2.6) \\
\quad 144(0.9), 149(1.5), 197 \\
(0.8)\end{array}$ \\
\hline & & $\begin{array}{l}2 \mathrm{~m} \text { urea }+50 \% \\
\text { acetonitrile }\end{array}$ & 110 & $\begin{array}{l}91 \text { (1.3), } 95 \text { (3.1), } 144(1.4) \\
\quad 149(1.5)\end{array}$ \\
\hline
\end{tabular}

a) Instrumental conditions: untreated fused-silica capillary $58.5 \mathrm{~cm}(50 \mathrm{~cm}$ to the detector window) $\times 50 \mu \mathrm{m}$ ID; UV-detection at $230 \mathrm{~nm} ; 20 \mathrm{kV}$

b) Temperature, $60^{\circ} \mathrm{C}$

c) Temperature, $45^{\circ} \mathrm{C}$ 


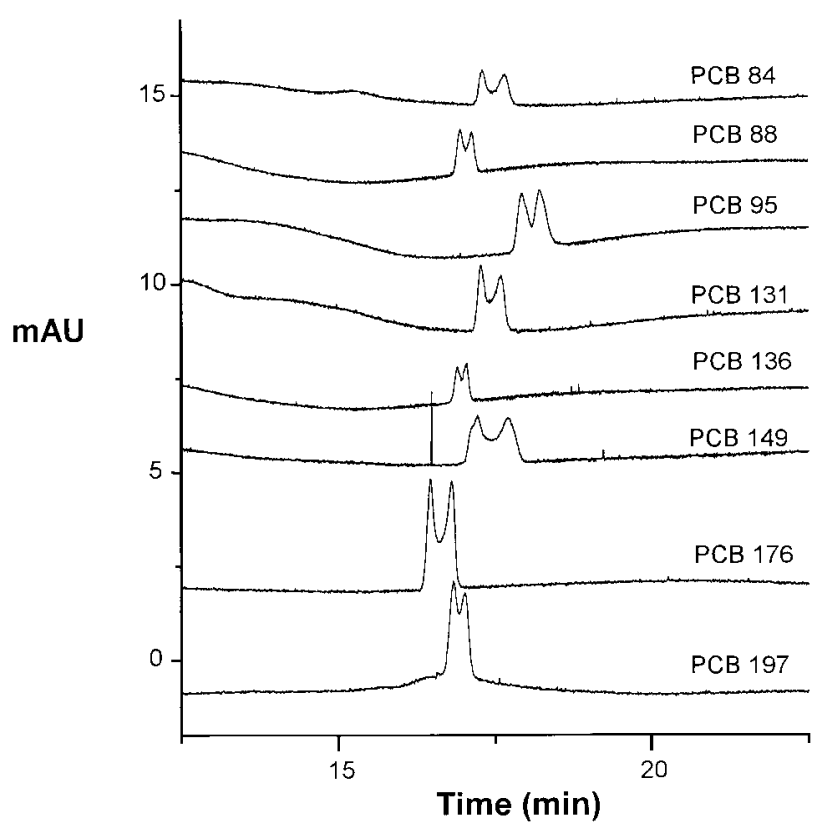

Figure 2. Electropherograms corresponding to the chiral recognition of PCBs 84, 88, 95, 131, 136, 149, 176 y 197 in $10 \mathrm{~mm}$ phosphate buffer $(\mathrm{pH} 2.0)$ containing $30 \mathrm{~mm}$ $\beta-\mathrm{CD}-\mathrm{NH}_{2}$ and $2 \mathrm{~m}$ urea. Other conditions as in Fig. 1.

and $2 \mathrm{M}$ urea at $60^{\circ} \mathrm{C}$ (see Table 3). These results may be due to the different temperature employed for the two buffer solutions. In fact, a general behavior when changing temperature is not observed for a chiral separation. Thus, a decrease or an increase in the chiral resolution may be obtained for different analytes when the temperature is varied [1].

On the other hand, the addition of $4 \mathrm{~m}$ urea decreased the number of PCBs chirally recognized probably due to the increasing viscosity of the separation buffer and current intensity. Figure 2 shows the chiral discrimination observed for PCBs in $10 \mathrm{~mm}$ phosphate buffer $(\mathrm{pH} 2.0)$ containing $30 \mathrm{~mm} \beta-\mathrm{CD}-\mathrm{NH}_{2}$ and $2 \mathrm{~m}$ urea. In this electropherogram broad peaks were observed. Then, in order to decrease the broadening of peaks as well as to increase the chiral resolution of $\mathrm{PCBs}$, different percentages of acetonitrile were used (10 and 50\%). Figure 3 shows the chiral resolution obtained with the different percentages of acetonitrile used. It can be observed that the addition of acetonitrile to $10 \mathrm{~mm}$ phosphate buffer $(\mathrm{pH} 2.0)$ containing $30 \mathrm{~mm} \beta-\mathrm{CD}$ $\mathrm{NH}_{2}$ and $2 \mathrm{M}$ urea enabled to increase the chiral resolution of PCB 91 (2,2',3,4',6-pentachloro), PCB 95 (2,2',3,5',6-pentachloro), PCB 136 (2,2',3,3',6,6'-hexachloro), PCB 144 (2,2',3,4,5',6-hexachloro), PCB 149 (2,2',3,4',5',6-hexachloro), and PCB 197 (2,2',3,3',4,4',6,6'-octachloro). Thus, Fig. 4 a shows the electropherograms obtained for PCB 136 (2,2',3,3',6,6'-hexachloro) and PCB 197 $\left(2,2^{\prime}, 3,3^{\prime}, 4,4^{\prime}, 6,6^{\prime}\right.$-octachloro) when $10 \%$ of acetonitrile

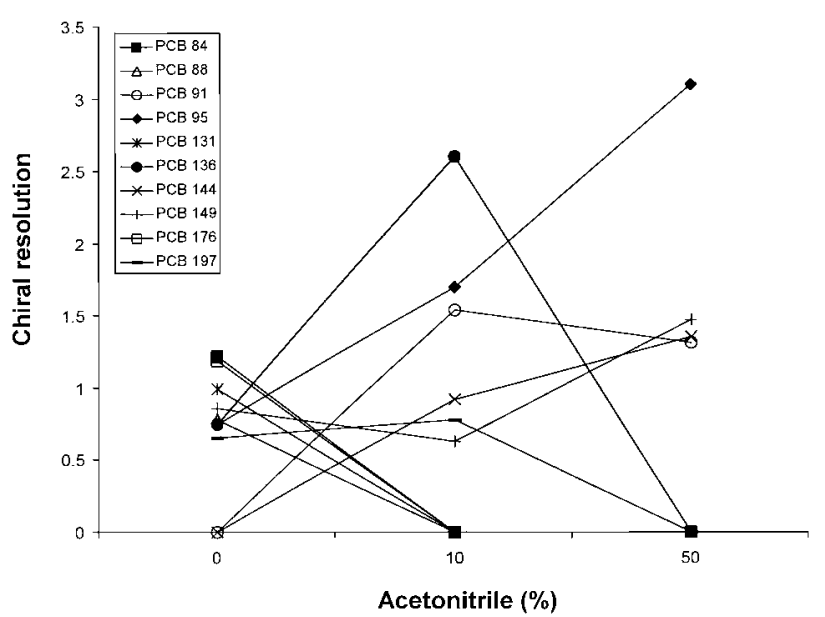

Figure 3. Chiral resolution obtained for PCBs as a function of the percentage of acetonitrile added to $10 \mathrm{~mm}$ phosphate $(\mathrm{pH} 2.0)$ containing $30 \mathrm{~mm} \beta-\mathrm{CD}-\mathrm{NH}_{2}$ and $2 \mathrm{M}$ urea. Other conditions as in Fig. 1.

was added to the separation solution. Figure $4 \mathrm{~b}$ shows the electropherograms obtained for PCB 91 (2,2',3,4',6pentachloro), PCB 95 (2,2',3,5',6-pentachloro), PCB 144 (2,2',3,4,5',6-hexachloro), and PCB 149 (2,2',3,4',5',6hexachloro) when $50 \%$ of acetonitrile was added to the separation solution. Although the addition of acetonitrile enables to improve the chiral resolution of some PCBs, the using of acetonitrile in the separation buffer increases the migration times of PCBs.

\section{Concluding remarks}

A different behavior was observed when different charged CDs were used as chiral selectors in electrokinetic chromatography $(E K C)$ for the chiral separation of highly hydrophobic neutral racemates of environmental interest such as atropisomeric polychlorinated biphenyls (PCBs). From the anionic CDs used in this work ( $\beta-C D$ phosphated, $\beta-C D$ sulfated, Succ- $\gamma-C D$ and Succ- $\beta$ $C D)$, only Succ- $\beta-C D$ enabled the chiral separation of some of PCBs studied. A slight chiral recognition of eight PCBs was observed with a phosphate buffer at $\mathrm{pH} 7.0$ containing $2 \mathrm{M}$ urea when Succ- $\beta-C D$ is used as chiral selector. The chiral resolution obtained under these conditions could not be improved through the use of different additives such as organic modifiers (acetonitrile or alcohols) or the addition of a second CD, such as $\beta-C D$.

The chiral recognition of 11 PCBs has been achieved using a phosphate buffer $(\mathrm{pH} 2.0)$ containing $2 \mathrm{M}$ urea and $\beta-\mathrm{CD}-\mathrm{NH}_{2}$ as chiral selector. The presence of $2 \mathrm{M}$ urea in the separation buffer was crucial since lower or higher concentrations of this additive decrease the chiral 

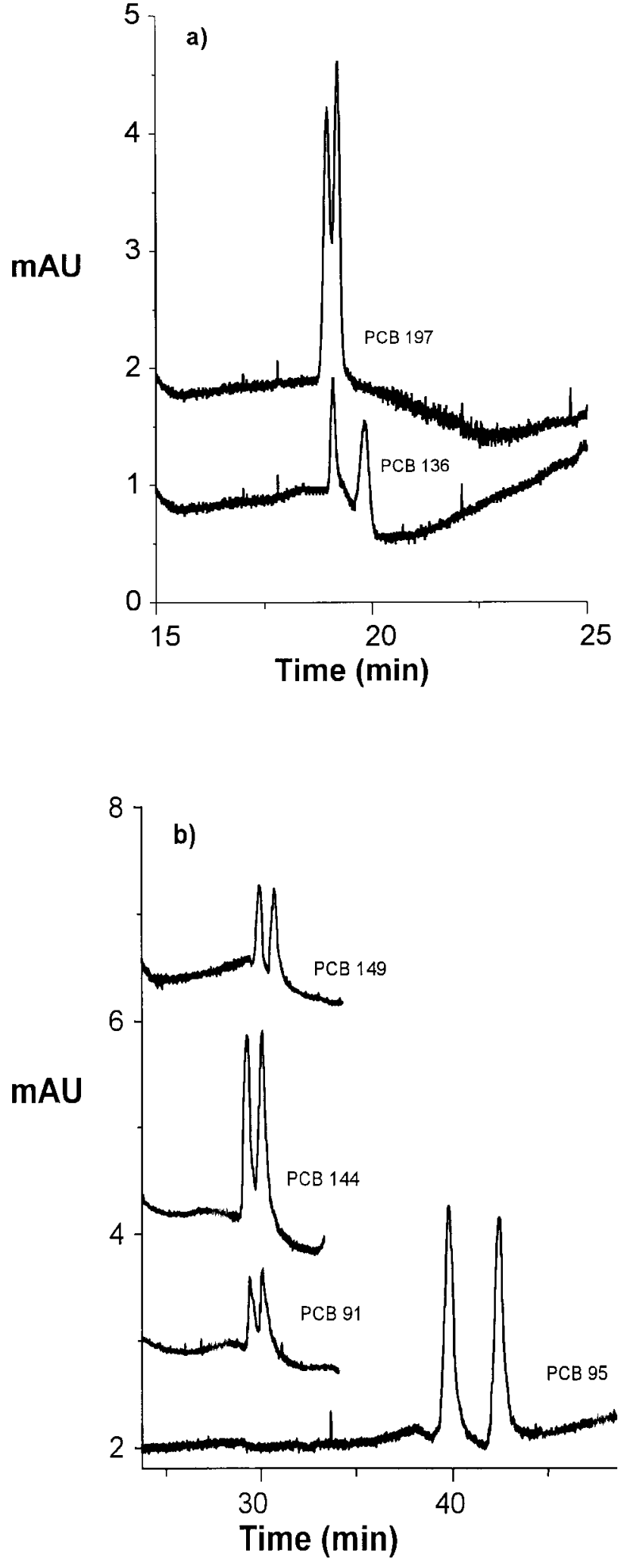

Figure 4. Electropherograms obtained with $30 \mathrm{~mm} \beta-\mathrm{CD}-$ $\mathrm{NH}_{2}$ in $10 \mathrm{~mm}$ phosphate $(\mathrm{pH} 2.0)$ containing $2 \mathrm{M}$ urea and (a) $10 \%$ acetonitrile or (b) $50 \%$ acetonitrile. Other conditions as in Fig. 1. resolution obtained for $\mathrm{PCBs}$ with this cationic $\mathrm{CD}$. A study of the effect of the addition of acetonitrile to the separation buffer showed that it is possible to increase the chiral resolution of PCB 91 (2,2',3,4',6-pentachloro), PCB 95 (2,2',3,5',6pentachloro), PCB 136 (2,2',3,3',6,6'-hexachloro), PCB 144 (2,2',3,4,5',6-hexachloro), PCB 149 (2,2',3,4',5',6-hexachloro), and PCB 197 (2,2',3,3',4,4',6,6'-octachloro) contrary to the results obtained with anionic CDs. In fact, $10 \%$ acetonitrile is the best choice because higher percentages of acetonitrile (50\%) cause a considerable increase in the migration times. On the other hand, the addition of $\beta-C D$ did not improve the chiral separation of PCBs as in the case of Succ- $\beta-C D$. The results obtained with both CDs Succ- $\beta$ $\mathrm{CD}$ and $\beta-\mathrm{CD}-\mathrm{NH}_{2}$ show that when a charged $\mathrm{CD}$ derivative acts as chiral selector it is not useful to add a second CD to work also as chiral selector, probably due to a competitive effect of both CDs as chiral selectors [44].

Our results show that the best conditions to achieve these separations are constituted by the use of a dual system $\mathrm{CM}-\gamma-\mathrm{CD} / \beta-\mathrm{CD}$ or by the use of $\beta-\mathrm{CD}-\mathrm{NH}_{2}$ alone in the separation buffer. While the cationic $C D$ enables the chiral discrimination of 11 PCBs by itself and urea and acetonitrile are crucial in order to increase the chiral resolution of PCBs, carboxymethyl- $\gamma-C D$ alone does not enable the chiral separation of any PCB. However, the addition of a neutral $C D$ such as $\beta-C D$ which decreases the chiral resolution obtained for PCBs with the cationic $C D$, enables the chiral separation of 13 of the PCBs studied with carboxymethyl- $\gamma$-CD originating an interesting dual system for the rapid chiral separation of $\mathrm{PCBs}$. Analysis times obtained for the cationic $C D$ were about 20 min while the dual system $\mathrm{CM}-\gamma-\mathrm{CD} / \beta-\mathrm{CD}$ enables the chiral separation of PCBs in analysis times $<12 \mathrm{~min}$ [41]. All the results obtained in the present and previous studies show the complexity of the interactions of a same group of solutes with chiral selectors of different nature and the difficulty to predict the most adequate chiral selector to a given separation. Thus, new research studies aimed at studying the analyte-CD interactions are necessary to understand the principles of the chiral recognition.

The authors thank the Comunidad Autónoma de Madrid (Spain) for project 07M/0049/1998.

Received January 15, 2003

\section{References}

[1] Chankvetadze, B., Capillary Electrophoresis in Chiral Analysis, John Wiley \& Sons, New York 1997.

[2] Chankvetadze, B., Blaschke, G., J. Chromatogr. A 2001, 906, 309-363.

[3] Fanali, S., J. Chromatogr. A 1997, 792, 227-267.

[4] Fanali, S., J. Chromatogr. A 2000, 875, 89-122. 
[5] De Boer, T., De Zeeuw, R. A., De Jong, G. J., Ensing, K., Electrophoresis 1999, 20, 2989-3010.

[6] Chankvetadze, B., J. Chromatogr. A 1997, 792, 269-295.

[7] O’Keeffe, F., Shamsi, S. A., Darcy, R., Schwinté, P. I., Warner, M., Anal. Chem. 1997, 69, 4773-4782.

[8] Haynes III, J. L., Shamsi, S. A., O’Keefe, F., Darcey, R., Warner, I. M., J. Chromatogr. A 1998, 803, 261-271.

[9] De Boer, T., De Zeeuw, R. A., De Jong, G. J., Ensing, K., Electrophoresis 2000, 21, 3220-3239.

[10] Terabe, S., TrAC 1989, 8, 129-134.

[11] Nardi, A., Eliseev, A., Boček, P., Fanali, S., J. Chromatogr. 1993, 638, 247-253.

[12] Fanali, S., Camera, E., Chromatographia 1996, 43, 247-253.

[13] Egashira, N., Mutoh, O., Kurauchi, Y., Ohga, K., Anal. Sci. 1996, 12, 503-505.

[14] Bunke, A., Jira, T., Pharmazie 1996, 51, 672-673.

[15] Lelièvre, F., Gareil, P., Jardy, A., Anal. Chem. 1997, 69, 385392.

[16] Lelièvre, F., Gareil, P., Bahaddi, P., Anal. Chem. 1997, 69, 393-401.

[17] Schulte, G., Chankvetadze, B., Blaschke, G., J. Chromatogr. A 1997, 771, 259-266.

[18] Jakubetz, H., Juza, M., Schurig, V., Electrophoresis 1997, 18, 897-904.

[19] Tanaka, Y., Terabe, S., J. Chromatogr. A 1997, 781, 151-160.

[20] Zhang, R., Zhang, H. X., Eaker, D., Hjertén, S., J. Capil. Electrophor. 1997, 4, 105-112.

[21] Galaverna, G., Corradine, R., Dossena, A., Marchelli, R., Vecchio, G., Electrophoresis 1997, 18, 905-911.

[22] Nair, U. B., Armstrong, D. W., Microchem. J. 1997, 57, 199217.

[23] Wang, F., Khaledi, M. G., Electrophoresis 1998, 19, 20952100.

[24] Wang, F., Khaledi, M. G., J. Chromatogr. A 1998, 817, 121128.

[25] Jakubetz, H., Juza, M., Schurig, V., Electrophoresis 1998, $19,738-744$.
[26] Bunke, A., Jira, T., J. Chromatogr. A 1998, 798, 275-280.

[27] Galaverna, G., Corradine, R., Dossena, A., Marchelli, R., Vecchio, G., Electrophoresis 1999, 20, 2619-2629.

[28] Wang, F., Loughlin, T., Dowling, T., Bicker, G., Wyvratt, J., J. Chromatogr. A 2000, 872, 279-288.

[29] Iványi, R., Jicsinszky, L., Juvancz, Z., Chromatographia 2001, 53, 166-172.

[30] Galaverna, G., Paganuzzi, M. C., Corradini, R., Dossena, A., Marchelli, R., Electrophoresis 2001, 22, 3171-3177.

[31] Iványi, R., Jicsinszky, L., Juvancz, Z., Electrophoresis 2001, 22, 3232-3236.

[32] González, M. J., Fernández, M. A., Hernández, L. M., Arch. Environ. Contam. Toxicol. 1991, 20, 343-348.

[33] Font, G., Mañes, J., Moltó, J. C., Picó, Y., J. Chromatogr. A 1996, 733, 449-471.

[34] Schurig, V., Glaush, A., Fluck, M., Tetrahedron: Asymmetry 1995, 6, 2161-2164.

[35] Schurig, V., Reich, S., Chirality 1998, 10, 316-320.

[36] Marina, M. L., Benito, I., Díez-Masa, J. C., González, M. J., Chromatographia 1996, 42, 269-272.

[37] Grainger, J., Liu, Z., Marano, K., Barr, J., Patterson Jr., D. G., Organohalogen Compounds 1997, 31, 286-291.

[38] Marina, M. L., Benito, I., Díez-Masa, J. C., González, M. J., J. Chromatogr. A 1996, 752, 265-270.

[39] Crego, A. L., González, M. J., Marina, M. L., Electrophoresis 1998, 19, 2113-2118.

[40] Crego, A. L., García, M. A., Marina, M. L., J. Microcol. Sep. 2000, 12, 33-40.

[41] García-Ruiz, C., Martín Biosca, Y., Crego, A. L., Marina, M. L., J. Chromatogr. A 2001, 910, 157-164.

[42] García-Ruiz, C., Andrés, R., Valera, J. L., Laborda, F., Marina, M. L., J. Sep. Sci. 2002, 25, 17-22.

[43] Ballschmiter, K., Zell, M., Fresenius' Z. Anal. Chem. 1980, 302, 20-31.

[44] Lurie, I. S., J. Chromatogr. A 1997, 792, 297-307.

[45] Schwer, C., Kenndler, E., Anal. Chem. 1991, 63, 1801-1807. 